\title{
Adiponectin Gene Variant rs266729 Interacts with Different Macronutrient Distribution of Two Different Hypocaloric Diets
}

\author{
Daniel Antonio de Luis David Primo Olatz Izaola Rocío Aller \\ Center of Investigation of Endocrinology and Nutrition, Medicine School and Department of Endocrinology and \\ Investigation, Hospital Clinico Universitario, University of Valladolid, Valladolid, Spain
}

\section{Keywords}

Adiponectin · Insulin resistance · Hypocaloric diet · Obesity · rs266729

\begin{abstract}
Background: The role of $A D I P O Q$ gene variants in weight loss after different dietary fat amounts remains unclear. $\mathbf{O b}$ jective: Our aim was to analyze the effects of $A D I P O Q$ gene polymorphism rs266729 on metabolic changes after two different amounts of dietary fat in two hypocaloric diets. Design: A population of 283 obese patients was recruited in a randomized clinical trial with two diets: Diet HF (high-fat diet: $38 \%$ carbohydrates, $24 \%$ proteins, and $38 \%$ fats) versus Diet LF (low-fat diet: 53\% carbohydrates, 20\% proteins, and $27 \%$ fats). Before and after 3 months, an anthropometric evaluation, an assessment of nutritional intake, and a biochemical analysis were carried out. The variant of the ADIPOQ gene was assessed by real-time PCR. Results: Weight loss was similar with both diets in both genotypes (CC vs. $\mathrm{CG}+\mathrm{GG}$ ). After dietary intervention with Diet HF, only subjects with CC genotype showed a significant improvement in insulin levels $(-3.3 \pm 0.6 \mathrm{vs} .-1.8 \pm 0.9 \mathrm{mU} / \mathrm{L} ; p=0.03)$ and the homeostasis model assessment for insulin resistance (HOMA-IR) $(-1.3 \pm 0.1$ vs. $-0.8 \pm 0.2$ units; $p=0.02)$. After Diet
\end{abstract}

LF, subjects with CC genotype showed a significant improvement in total cholesterol levels (CC vs. CG+GG) $(-15.3 \pm 1.4$ vs. $-6.4 \pm 1.3 \mathrm{mg} / \mathrm{dL} ; p=0.01)$, LDL cholesterol $(-14.6 \pm 1.8$ vs. $-6.4 \pm 1.3 \mathrm{mg} / \mathrm{dL} ; p=0.01)$, insulin levels $(-4.6 \pm 1.0$ vs. $-1.6 \pm 0.5 \mathrm{mU} / \mathrm{L} ; p=0.01)$, and HOMA-IR $(-1.6 \pm 0.1$ vs. $-1.0 \pm$ 0.2 units; $p=0.02$ ). Only subjects with CC genotype showed a significant increase of adiponectin levels after both diets (CC vs. CG+GG): Diet HF (10.6 \pm 2.0 vs. $1.8 \pm 1.0 \mathrm{ng} / \mathrm{dL} ; p=$ $0.01)$ and Diet LF (16.1 \pm 2.8 vs. $1.3 \pm 1.0 \mathrm{ng} / \mathrm{dL}: p=0.03)$. Conclusion: CC genotype of ADIPOQ gene variant rs266729 was associated with a better metabolic response after both diets. Additionally, Diet LF produced a significant improvement in lipid profile in noncarriers of allele $G$.

(c) 2019 The Author(s)
Published by S. Karger AG, Basel

\section{Introduction}

Adipose tissue stores fat during energy surplus, but it is also a key endocrine organ secreting adipokines involved in the regulation of metabolism and energy homeostasis. Adiponectin is the most quantitatively abundant adipokine secreted by adipocytes. The functions of adiponectin in lipid and glucose metabolism, vascular en-

\begin{tabular}{|c|c|}
\hline KARGER & $\begin{array}{l}\text { (c) } 2019 \text { The Author(s) } \\
\text { Published by S. Karger AG, Basel }\end{array}$ \\
\hline $\begin{array}{l}\text { E-Mail karger@karger.com } \\
\text { www.karger.com/lfg }\end{array}$ & $\begin{array}{l}\text { This article is licensed under the Creative Commons Attribution- } \\
\text { NonCommercial-NoDerivatives } 4.0 \text { International License (CC BY- } \\
\text { NC-ND) (http://www.karger.com/Services/OpenAccessLicense). } \\
\text { Usage and distribution for commercial purposes as well as any dis- } \\
\text { tribution of modified material requires written permission. }\end{array}$ \\
\hline
\end{tabular}

Dr. D.A. de Luis

Executive Director of Institute of Endocrinology and Nutrition

Medicine School, Valladolid University

C/Los Perales 16, Simancas, ES-47130 Valladolid (Spain)

E-Mail dadluis@yahoo.es 
dothelial cells, and macrophages [1] confer protection against obesity, and concentrations of adiponectin are reduced in obese subjects.

Serum adiponectin levels have a strong genetic composition, with heritability estimated at $80 \%$ [2]. Adiponectin is encoded by adiponectin C1Q and the collagen domain containing (ADIPOQ) gene, which is located on chromosome 3q27. Single nucleotide polymorphisms (SNPs) associated with serum adiponectin and insulin resistance have been described [3]. The most common SNP of this gene is rs $266729(-11,377 \mathrm{C}>\mathrm{G})$, it is located in the proximal promoter region of the $A D I P O Q$ gene. Data in the literature indicate that $A D I P O Q$ rs266729 polymorphism functionally regulates adiponectin promoter activity and adiponectin levels $[4,5]$. This $A D I P O Q$ variant has been identified to be associated with high body mass index (BMI) and insulin resistance [6-8].

The interaction of this SNP with dietary intake has been demonstrated $[9,10]$, but few studies have compared two different dietary interventions. For example, the Finnish Diabetes Prevention Study showed that the genetic variant of the ADIPOQ gene rs 266729 contributes to variation in body weight and serum adiponectin concentrations [9]. After weight loss with a hypocaloric Mediterranean diet, this genetic variant (rs266729) was associated with changes in adiponectin levels, insulin resistance, and lipid profile [10]. The interaction of this SNP with other weight loss interventions has been evaluated, such as sibutramine [11] and different bariatric surgery techniques $[12,13]$. These studies have shown different results depending on the weight loss and the duration of the intervention. It is important to note, therefore, that assessing a hypocaloric dietary intervention with two significantly different amounts of fat (differences of fat greater than 5\%) can improve our knowledge concerning the interaction of this SNP with the diet. Because the two previous studies $[9,10]$ in the literature used dietary interventions with calorie restriction and low-fat intake (around 25\% of the total caloric intake), the use of highfat hypocaloric diets may offer different results.

Our aim was to analyze the effects of $A D I P O Q$ gene polymorphism rs266729 on metabolic changes after two different amounts of dietary fat in two hypocaloric diets.

\section{Subjects and Methods}

\section{Subjects and Clinical Investigation}

We carried out a prospective study approved by our Ethics Committee (HCUVA Committee, May 2017) which was in accordance with the guidelines laid down in the Declaration of Helsinki.
The recruitment of 283 obese patients was a consecutive method of sampling among subjects sent from primary care physicians to treat obesity in a randomized clinical trial with two different diets. Data of these subjects were collected at the beginning and after 3 months of dietary interventions and all participants provided written informed consent. All the recruited patients fulfilled the following inclusion criteria: age between 20 and 60 years and BMI $\geq 30 \mathrm{~kg} / \mathrm{m}^{2}$. The exclusion criteria were any of the following: history of thyroid disease, heart attack, ictus, severe renal or hepatic disorders, active alcoholism, or malignant tumor, and receiving medications known to influence lipid (hormonal therapy, glucocorticoids, and anti-inflammatory drugs) or glucose levels (sulfonylureas, thiazolidinedione, insulin, GLP-1 receptor antagonists, S-GLT2, DPP-IV inhibitors, and metformin) within the 3 months before the study.

The first endpoint was body weight loss after 3 months versus baseline. The second endpoints were changes on lipid profile, insulin levels, insulin resistance, and serum adiponectin. All anthropometric parameters (weight, height, BMI, waist circumference, fat mass by impedance) and blood pressure were recorded at baseline and after 3 months. Blood samples were collected in EDTAtreated and plain tubes after a 10-h overnight fast for analysis of CRP, insulin, total cholesterol, LDL cholesterol, HDL cholesterol, triglycerides, leptin, total adiponectin, and resistin levels. The $A D I P O Q$ gene variant was assessed by real-time PCR.

\section{Dietary Intervention}

Both diets were designed to produce about $500 \mathrm{kcal} /$ day less than individually estimated total energy expenditure. As previously mentioned, patients were randomly allocated to one of two diets for a period of 3 months. The target composition of Diet HF (highfat diet) was $38 \%$ carbohydrates, $24 \%$ proteins, and $38 \%$ fats. Diet LF (low-fat diet) was composed of $53 \%$ carbohydrates, $20 \%$ proteins, and $27 \%$ fats. The fat profile of both diets was similar $(45 \%$ monounsaturated fatty acids, $30 \%$ saturated fatty acids, and $25 \%$ polyunsaturated fatty acids), the main difference being the total amount of fat (38 vs. $27 \%$ ). All participants had three individual sessions (25 min with diet sheets and example menu plans) with the dietitian at the start of the trial to explain the diet. Food tables were used with a Mediterranean pattern including legumes, vegetables, poultry, fish, and fresh fruit, using olive oil. This dietitian assessed the adherence to this diet every 7 days with a phone call. All enrolled subjects were instructed to record their daily dietary intake for 3 nonconsecutive days including a weekend day. These groups of three dietary records were collected 2 weeks prior to the randomization (data to obtain the basal diet) and each month during the randomization (data to obtain the diet intervention). A dietitian assessed this adherence every 7 days with a phone call in order to improve compliance. Records were analyzed with a computer-based data evaluation system (Dietosource ${ }^{\circledR}, \mathrm{Ge}, \mathrm{Swi}$ ) [14]. Finally, the recommended physical activity consisted of an aerobic exercise at least 2 times per week (60 min each).

\section{Biochemical and Adipokine Assays}

Blood samples for the analysis of parameters were drawn after a minimum of $10 \mathrm{~h}$ overnight fasting and serum was stored at $-80^{\circ} \mathrm{C}$ until analyzed. Plasma glucose level was carried out using an automated glucose oxidase method (Glucose Analyzer 2; Beckman Instruments, Fullerton, CA, USA) using reagents supplied by the manufacturer. Insulin was measured by radioimmunoanalysis 
(RIA Diagnostic Corporation, Los Angeles, CA, USA) with a sensitivity of $0.5 \mathrm{mUI} / \mathrm{L}$ (normal range $0.5-30 \mathrm{mUI} / \mathrm{L}$ ) [15], and the homeostasis model assessment for insulin resistance (HOMA-IR) was calculated using these values with the following formula: HOMA-IR $=($ glucose $\times$ insulin/22.5) [16] .

The method used for the measurement of plasma lipid concentrations was the enzymatic colorimetric assay (Technicon Instruments, Ltd., New York, NY, USA), while HDL cholesterol was determined enzymatically in the supernatant after precipitation of other lipoproteins with dextran sulphate-magnesium. LDL cholesterol was calculated using the Friedewald formula [17].

Serum adipokine levels were determined using enzyme-linked immunosorbent assays (ELISA). Resistin was measured by ELISA (Biovendor Laboratory, Inc., Brno, Czech Republic) with a sensitivity of $0.2 \mathrm{ng} / \mathrm{mL}$ (normal range $4-12 \mathrm{ng} / \mathrm{mL}$ ) [18]. Leptin was measured by ELISA (Diagnostic Systems Laboratories, Inc., TX, USA) with a sensitivity of $0.05 \mathrm{ng} / \mathrm{mL}$ (normal range $10-100 \mathrm{ng}$ / $\mathrm{mL}$ ) [19]. Adiponectin was measured by ELISA (R\&D Systems, Inc., Minneapolis, MN, USA) with a sensitivity of $0.246 \mathrm{ng} / \mathrm{mL}$ (normal range $8.65-21.43 \mathrm{ng} / \mathrm{mL}$ ) [20].

\section{Genotyping ADIPOQ Gene}

Buffy coats removed from blood samples were stored in EDTA at $-80^{\circ} \mathrm{C}$. Genomic DNA was extracted from $150 \mu \mathrm{L}$ buffy coat using QIAamp ${ }^{\circledR}$ DNA blood kit following the manufacturer's instructions. Oligonucleotide primers and probes were designed with the Beacon Designer 5.0 (Premier Biosoft International ${ }^{\circledR}$, Los Angeles, CA, USA). The PCR was carried out with $50 \mathrm{ng}$ of genomic DNA and $0.5 \mu \mathrm{L}$ of each oligonucleotide primer (forward: $5^{\prime}$ - ACGTTGGATGATGTGTGGCTTGCAAGAACC $-3^{\prime}$ and reverse $5^{\prime}$ - ACGTTGGATGCAACATTCAACACCTTGGAC - $3^{\prime}$ ) in a 2- $\mu \mathrm{L}$ final volume (Termociclador Life Technologies, Los Angeles, CA, USA). DNA was denatured at $90^{\circ} \mathrm{C}$ for $2 \mathrm{~min}$; this was followed by 50 cycles of denaturation at $90^{\circ} \mathrm{C}$ for $20 \mathrm{~s}$ and annealing at $56.1^{\circ} \mathrm{C}$ for $50 \mathrm{~s}$ ). The PCR were run in a $25-\mu \mathrm{L}$ final volume containing $10.5 \mu \mathrm{L}$ of IQTM Supermix (Bio-Rad ${ }^{\circledR}$, Hercules, CA, USA) with Hot Start Taq DNA polymerase. We used internal controls, and the accuracy was assessed by inclusion of duplicates in the arrays. Hardy-Weinberg equilibrium was assessed with a statistical test ( $\chi^{2}$ test) to compare our expected and observed counts. The variant was in Hardy-Weinberg equilibrium $(p=0.33)$.

\section{Anthropometric Parameters and Blood Pressure}

Determination

Physical examinations, including body weight and height measurements, were performed. Body height was measured using a standing stadiometer with a precision of $1 \mathrm{~mm}$ (Omrom, Los Angeles, CA, USA). Body weight was measured in the morning while the subjects were minimally clothed to the nearest $0.1 \mathrm{~kg}$ and not wearing shoes (Omrom). BMI was calculated as body weight (in $\mathrm{kg}$ ) divided by height (in $\mathrm{m}^{2}$ ). Waist circumference was measured with a flexible nonstretchable measuring tape (Type SECA; SECA, Birmingham, UK). Bioimpedance was used to determine body composition with an accuracy of $5 \mathrm{~g}$ [21] (EFG; Akern, Italy). Blood pressure was measured twice after a 5 -min rest with a random zero mercury sphygmomanometer (Omrom) and averaged.

Statistical Analysis

Sample size was calculated to detect changes over $10 \mathrm{ng} / \mathrm{mL}$ in adiponectin levels with $90 \%$ power and $5 \%$ significance $(n=130$ in each dietary group). Parameters with normal distribution were analyzed with a two-tailed Student $t$ test. Nonparametric parameters were analyzed with the Mann-Whitney U test. Categorical variables were analyzed with the $\chi^{2}$ test, with Yates correction as necessary, and the Fisher exact test. The statistical analysis used to evaluate the gene-diet interaction was a univariate ANCOVA using gender and baseline weight. For correction of multiple hypotheses testing for single SNPs, analysis was performed with the Dale discovery rate method. A $\chi^{2}$ test was used to evaluate the HardyWeinberg equilibrium. All analyses were performed under a dominant genetic model with rs266729 $\mathrm{G}$ allele as the risk allele (GG+GC vs. CC). A $p$ value $<0.05$ was considered significant. All the data were analyzed using SPSS for Windows version 19.0 software package (SPSS Inc. Chicago, IL, USA).

\section{Results}

A total of 283 obese subjects were enrolled in the study: 169 CC (59.7\%), 95 CG (33.6\%), and 19 GG (6.7\%). All patients completed the 3-month follow-up period. The mean age of the total group was $48.2 \pm 6.2$ years (range: $27-65$ ) and the mean BMI was $37.0 \pm 4.1 \mathrm{~kg} / \mathrm{m}^{2}$ (range: 31.5-40.1). Sex distribution was 207 women (73.1\%) and 76 men (26.9\%). Age was similar in both genotype groups (wild type [CC] vs. mutant type [CG+GG]: $48.4 \pm 6.1$ vs. $47.9 \pm 5.0$ years; nonsignificant). Sex distribution was similar in both genotype groups (males 30.6 vs. $27.5 \%$ and females 69.4 vs. $72.5 \%$, respectively).

A total of 134 subjects (81 CC as wild genotype and 45 CG/8 GG as mutant genotype [CG+GG]) were treated with Diet HF. The basal dietary intake with a 3-day written food record of this group showed a calorie intake of $1,943.2 \pm 292.1 \mathrm{kcal} /$ day, a carbohydrate intake of $183.2 \pm$ $16.9 \mathrm{~g} /$ day ( $42.3 \%$ of calories), a fat intake of $81.4 \pm 9.0 \mathrm{~g} /$ day (38.1\% of calories), and a protein intake of $87.1 \pm 7.0$ $\mathrm{g} /$ day (19.633\% of calories). During the intervention, these subjects reached the recommendations of Diet HF: $1,340.9 \pm 113.3 \mathrm{kcal} /$ day, $37.3 \%$ carbohydrates $(124.5 \mathrm{~g} /$ day), $26.0 \%$ proteins ( $87.2 \mathrm{~g} /$ day), and $36.7 \%$ fats $(61.3 \mathrm{~g} /$ day). Physical activity was similar in both genotype groups $(57.7 \pm 19.3$ vs. $58.1 \pm 16.1 \mathrm{~min} /$ week; $p=0.76)$.

A total of 149 obese patients (88 CC as wild genotype and $50 \mathrm{CG} / 11 \mathrm{GG}$ as mutant genotype [CG+GG]) were treated with Diet LF. The basal dietary intake showed a calorie intake of $1716.2 \pm 118.9 \mathrm{kcal} /$ day, a carbohydrate intake of $170.3 \pm 28.1 \mathrm{~g} /$ day ( $42.9 \%$ of calories), a fat intake of $80.0 \pm 7.9 \mathrm{~g} /$ day ( $36.3 \%$ of calories), and a protein intake of $90.5 \pm 9.3 \mathrm{~g} /$ day ( $20.8 \%$ of calories). During the intervention, these subjects reached the recommendations of Diet LF: 1,319 $\pm 143.8 \mathrm{kcal} /$ day, $53.3 \%$ carbohydrates ( $175.5 \mathrm{~g} /$ day), $20.9 \%$ proteins $(68.7 \mathrm{~g} /$ day), and 
Table 1. Anthropometric variables and blood pressure at baseline and after both dietary interventions

\begin{tabular}{|c|c|c|c|c|c|c|c|c|c|c|}
\hline \multirow[t]{4}{*}{ Characteristics } & \multicolumn{10}{|l|}{ rs 266729} \\
\hline & \multicolumn{4}{|c|}{ Diet HF $(n=134)$} & \multirow{3}{*}{$\begin{array}{l}p \\
\text { (time, } \\
\text { genotype, } \\
\text { genotype } \\
\times \text { time) }\end{array}$} & \multicolumn{4}{|c|}{ Diet LF $(n=149)$} & \multirow{3}{*}{$\begin{array}{l}p \\
\text { (time, } \\
\text { genotype, } \\
\text { genotype } \\
\times \text { time) }\end{array}$} \\
\hline & \multicolumn{2}{|c|}{$\mathrm{CC}(n=81)$} & \multicolumn{2}{|c|}{$\mathrm{CG}+\mathrm{GG}(n=53)$} & & \multicolumn{2}{|c|}{$\mathrm{CC}(n=88)$} & \multicolumn{2}{|c|}{$\mathrm{CG}+\mathrm{GG}(n=61)$} & \\
\hline & baseline & 3 months & baseline & 3 months & & baseline & 3 months & baseline & 3 months & \\
\hline BMI & $37.1 \pm 5.0$ & $35.6 \pm 4.1^{*}$ & $36.8 \pm 5.1$ & $35.4 \pm 4.1^{*}$ & $\begin{array}{l}0.02 \\
0.29 \\
0.03\end{array}$ & $36.9 \pm 5.1$ & $35.6 \pm 4.1^{*}$ & $36.8 \pm 4.2$ & $35.4 \pm 4.0^{*}$ & $\begin{array}{l}0.01 \\
0.38 \\
0.02\end{array}$ \\
\hline Weight, kg & $95.6 \pm 4.1$ & $90.8 \pm 4.0^{\mathrm{x}}$ & $93.7 \pm 10.0$ & $89.7 \pm 8.1^{x}$ & $\begin{array}{l}0.01 \\
0.38 \\
0.02\end{array}$ & $92.5 \pm 8.2$ & $88.5 \pm 6.1^{\mathrm{x}}$ & $91.2 \pm 7.2$ & $86.9 \pm 7.1^{\mathrm{x}}$ & $\begin{array}{l}0.01 \\
0.47 \\
0.02\end{array}$ \\
\hline Fat mass, kg & $40.8 \pm 5.0$ & $38.7 \pm 4.1^{\#}$ & $39.3 \pm 8.0$ & $37.2 \pm 9.0^{\#}$ & $\begin{array}{l}0.01 \\
0.24 \\
0.03\end{array}$ & $41.2 \pm 6.0$ & $38.3 \pm 4.9^{\#}$ & $41.3 \pm 4.1$ & $38.4 \pm 5.1^{\#}$ & $\begin{array}{l}0.02 \\
0.51 \\
0.03\end{array}$ \\
\hline WC, $\mathrm{cm}$ & $109.2 \pm 7.1$ & $106.2 \pm 5.3^{\&}$ & $110.1 \pm 6.0$ & $106.3 \pm 5.1^{\&}$ & $\begin{array}{l}0.02 \\
0.48 \\
0.04\end{array}$ & $109.7 \pm 8.0$ & $106.4 \pm 6.2^{\&}$ & $107.2 \pm 8.1$ & $104.1 \pm 4.3^{\&}$ & $\begin{array}{l}0.01 \\
0.28 \\
0.02\end{array}$ \\
\hline SBP, mm Hg & $126.5 \pm 3.1$ & $123.4 \pm 4.1^{* *}$ & $126.2 \pm 4.1$ & $123.1 \pm 3.0^{* *}$ & $\begin{array}{l}0.01 \\
0.24 \\
0.03\end{array}$ & $127.3 \pm 6.1$ & $124.0 \pm 6.0^{* *}$ & $127.1 \pm 7.0$ & $123.0 \pm 7.2^{* *}$ & $\begin{array}{l}0.02 \\
0.41 \\
0.03\end{array}$ \\
\hline DBP, mm Hg & $82.1 \pm 5.1$ & $82.1 \pm 4.1$ & $80.1 \pm 6.0$ & $79.6 \pm 5.0$ & $\begin{array}{l}0.45 \\
0.63 \\
0.60\end{array}$ & $83.8 \pm 5.1$ & $82.2 \pm 5.1$ & $83.4 \pm 5.0$ & $81.5 \pm 5.1$ & $\begin{array}{l}0.59 \\
0.73 \\
0.50\end{array}$ \\
\hline
\end{tabular}

Values are mean \pm SD. Diet HF, high-fat diet; Diet LF, low-fat diet; BMI, body mass index; DBP, diastolic blood pressure; SBP, systolic blood pressure; WC, waist circumference. Statistical differences in each genotype group: ${ }^{*}$ BMI, ${ }^{\mathrm{x}}$ weight, ${ }^{*}$ fat mass, ${ }^{\&} \mathrm{WC},{ }^{* *} \mathrm{SBP}$. There were no statistical differences between genotype groups.

Table 2. Biochemical parameters at baseline and after both dietary interventions

\begin{tabular}{|c|c|c|c|c|c|c|c|c|c|c|}
\hline \multirow[t]{4}{*}{ Characteristics } & \multicolumn{10}{|l|}{ rs266729 } \\
\hline & \multicolumn{4}{|c|}{ Diet HF $(n=134)$} & \multirow{3}{*}{$\begin{array}{l}p \\
\text { (time, } \\
\text { genotype, } \\
\text { genotype } \\
\times \text { time) }\end{array}$} & \multicolumn{4}{|c|}{ Diet LF $(n=149)$} & \multirow{3}{*}{$\begin{array}{l}p \\
\text { (time, } \\
\text { genotype, } \\
\text { genotype } \\
\times \text { time) }\end{array}$} \\
\hline & \multicolumn{2}{|l|}{$\mathrm{CC}(n=81)$} & \multicolumn{2}{|c|}{$\mathrm{CG}+\mathrm{GG}(n=53)$} & & \multicolumn{2}{|l|}{$\mathrm{CC}(n=88)$} & \multicolumn{2}{|c|}{$\mathrm{CG}+\mathrm{GG}(n=61)$} & \\
\hline & baseline & 3 months & baseline & 3 months & & baseline & 3 months & baseline & 3 months & \\
\hline Glucose, $\mathrm{mg} / \mathrm{dL}$ & $97.8 \pm 11.2$ & $95.6 \pm 7.0$ & $100.7 \pm 8.1$ & $97.0 \pm 7.2$ & $\begin{array}{l}0.12 \\
0.18 \\
0.24\end{array}$ & $100.6 \pm 8.1$ & $99.1 \pm 8.0$ & $101.1 \pm 10.2$ & $99.9 \pm 8.2$ & $\begin{array}{l}0.21 \\
0.40 \\
0.32\end{array}$ \\
\hline $\begin{array}{l}\text { Total cholesterol, } \\
\mathrm{mg} / \mathrm{dL}\end{array}$ & $199.3 \pm 13.1$ & $192.1 \pm 9.2^{\$}$ & $203.5 \pm 12.1$ & $194.9 \pm 11.2$ & $\begin{array}{l}0.14 \\
0.36 \\
0.34\end{array}$ & $204.5 \pm 8.1$ & $189.2 \pm 7.0^{\$}$ & $195.9 \pm 11.9$ & $189.8 \pm 12.1$ & $\begin{array}{l}0.01 \\
0.14 \\
0.02\end{array}$ \\
\hline $\begin{array}{l}\text { LDL-cholesterol, } \\
\mathrm{mg} / \mathrm{dL}\end{array}$ & $118.7 \pm 8.3$ & $112.8 \pm 9.1^{5 \%}$ & $127.4 \pm 18.1$ & $121.3 \pm 10.2$ & $\begin{array}{l}0.13 \\
0.33 \\
0.22\end{array}$ & $121.2 \pm 18.0$ & $106.6 \pm 10.1^{\%}$ & $120.8 \pm 22.1$ & $114.4 \pm 10.1$ & $\begin{array}{l}0.03 \\
0.21 \\
0.04\end{array}$ \\
\hline $\begin{array}{l}\text { HDL-cholesterol, } \\
\mathrm{mg} / \mathrm{dL}\end{array}$ & $52.4 \pm 6.0$ & $51.4 \pm 5.1$ & $50.1 \pm 5.0$ & $49.6 \pm 4.1$ & $\begin{array}{l}0.21 \\
0.52 \\
0.31\end{array}$ & $52.7 \pm 4.2$ & $52.5 \pm 4.0$ & $48.8 \pm 9.0$ & $48.0 \pm 7.1$ & $\begin{array}{l}0.21 \\
0.49 \\
0.28\end{array}$ \\
\hline Triglycerides, mg/dL & $132.3 \pm 21.1$ & $128.1 \pm 12.2$ & $124.9 \pm 28.2$ & $128.5 \pm 10.2$ & $\begin{array}{l}0.52 \\
0.78 \\
0.41\end{array}$ & $138.1 \pm 21.1$ & $132.6 \pm 12.2$ & $139.1 \pm 11.9$ & $135.2 \pm 8.1$ & $\begin{array}{l}0.61 \\
0.83 \\
0.33\end{array}$ \\
\hline $\mathrm{CRP}, \mathrm{ng} / \mathrm{dL}$ & $4.5 \pm 3.1$ & $4.6 \pm 2.1$ & $5.3 \pm 3.1$ & $5.1 \pm 2.8$ & $\begin{array}{l}0.43 \\
0.59 \\
0.18\end{array}$ & $6.0 \pm 3.1$ & $5.9 \pm 2.3$ & $6.1 \pm 3.0$ & $5.9 \pm 3.1$ & $\begin{array}{l}0.58 \\
0.69 \\
0.41\end{array}$ \\
\hline Insulin, mUI/L & $17.7 \pm 2.1$ & $14.4 \pm 3.1^{\#}$ & $16.4 \pm 6.9$ & $14.6 \pm 7.1$ & $\begin{array}{l}0.02 \\
0.33 \\
0.03\end{array}$ & $17.7 \pm 6.0$ & $13.1 \pm 4.2^{\#}$ & $15.9 \pm 6.0$ & $14.3 \pm 8.0$ & $\begin{array}{l}0.01 \\
0.28 \\
0.03\end{array}$ \\
\hline HOMA-IR & $4.4 \pm 1.1$ & $3.1 \pm 1.2^{8}$ & $4.3 \pm 2.1$ & $3.5 \pm 1.0$ & $\begin{array}{l}0.01 \\
0.21 \\
0.02\end{array}$ & $4.5 \pm 1.1$ & $2.9 \pm 1.2^{8}$ & $4.1 \pm 2.1$ & $3.1 \pm 2.1$ & $\begin{array}{l}0.01 \\
0.16 \\
0.02\end{array}$ \\
\hline
\end{tabular}

Values are mean \pm SD. Diet HF, high-fat diet; Diet LF, low-fat diet; CRP, C-reactive protein; HOMA-IR, homeostasis model assessment for insulin resistance. Statistical differences in each genotype group: ${ }^{\#}$ insulin, ${ }^{\&}$ HOMA IR, ${ }^{8}$ total cholesterol, ${ }^{\%}$ LDL cholesterol. There were no statistical differences between genotype groups. 
Table 3. Adipokines and cytokine levels

\begin{tabular}{|c|c|c|c|c|c|c|c|c|c|c|}
\hline \multirow[t]{3}{*}{ Characteristics } & \multicolumn{10}{|l|}{ rs266729 } \\
\hline & \multicolumn{4}{|c|}{ Diet HF $(n=134)$} & \multirow{2}{*}{$\begin{array}{l}p \\
\text { (time, } \\
\text { genotype, } \\
\text { genotype } \\
\times \text { time) }\end{array}$} & \multicolumn{4}{|c|}{ Diet LF $(n=149)$} & \multirow{2}{*}{$\begin{array}{l}p \\
\text { (time, } \\
\text { genotype, } \\
\text { genotype } \\
\times \text { time) }\end{array}$} \\
\hline & baseline & 3 months & baseline & 3 months & & baseline & 3 months & baseline & 3 months & \\
\hline $\begin{array}{l}\text { Adiponectin, } \\
\text { ng/dL }\end{array}$ & $9.6 \pm 4.0$ & $20.2 \pm 5.1^{*}$ & $10.1 \pm 3.9$ & $11.9 \pm 4.1$ & $\begin{array}{l}0.02 \\
0.14 \\
0.03\end{array}$ & $10.1 \pm 4.1$ & $27.2 \pm 5.3^{*}$ & $11.9 \pm 8.1$ & $13.2 \pm 9.1$ & $\begin{array}{l}0.01 \\
0.26 \\
0.02\end{array}$ \\
\hline
\end{tabular}

Values are mean \pm SD. Diet HF, high-fat diet; Diet LF, low-fat diet. ${ }^{*} p<0.05$, in each genotype group.

$25.8 \%$ fats ( $37.7 \mathrm{~g} /$ day). No statistical differences were detected in physical activity $(59.1 \pm 17.3 \mathrm{vs.} 60.3 \pm 21.9 \mathrm{~min} /$ week; $p=0.58$ ).

As indicated in Table 1, there were no significant genotype-related differences (baseline and after dietary intervention) in anthropometric parameters and blood pressure. After both dietary caloric restriction strategies with two different amounts of dietary fatty acids (Diet HF vs. Diet LF), body weight, BMI, fat mass, waist circumference, and systolic blood pressure decreased. Obese patients with both genotypes (CC vs. CG+GG) after Diet HF showed similar improvement: body weight $(-4.8 \pm 1.1$ vs. $-4.1 \pm 1.7 \mathrm{~kg} ; p=0.28)$, BMI $(-1.5 \pm 0.3$ vs. $-1.4 \pm 0.4 \mathrm{~kg} /$ $\left.\mathrm{m}^{2} ; p=0.26\right)$, fat mass $(-2.1 \pm 1.3$ vs. $-2.0 \pm 1.1 \mathrm{~kg} ; p=$ $0.51)$, waist circumference $(-3.1 \pm 1.0$ vs. $-3.0 \pm 0.9 \mathrm{~cm}$; $p=0.33)$, and systolic blood pressure $(-3.1 \pm 2.0$ vs. -3.2 $\pm 1.9 \mathrm{~mm} \mathrm{Hg} ; p=0.28)$. After caloric restriction with Diet LF, both genotype groups (CC vs. CG+GG) also showed also similar improvements: body weight $(-4.0 \pm 1.1$ vs. $-4.2 \pm 1.4 \mathrm{~kg} ; p=0.36)$, BMI $(-1.3 \pm 0.2$ vs. $-1.4 \pm 0.4 \mathrm{~kg} /$ $\left.\mathrm{m}^{2} ; p=0.22\right)$, fat mass $(-2.9 \pm 1.3$ vs. $-2.9 \pm 1.2 \mathrm{~kg} ; p=$ $0.59)$, waist circumference $(-3.3 \pm 1.2$ vs. $-3.1 \pm 1.3 \mathrm{~cm}$; $p=0.43)$, and systolic blood pressure $(-3.3 \pm 2.1$ vs. -4.1 $\pm 2.0 \mathrm{~mm} \mathrm{Hg} ; p=0.37$ ).

Table 2 shows biochemical parameters. After dietary intervention with a high-fat hypocaloric diet (Diet HF), only subjects with CC genotype showed a significant improvement in insulin levels $(-3.3 \pm 0.6$ vs. $-1.8 \pm 0.9$ $\mathrm{mU} / \mathrm{L} ; p=0.03)$ and HOMA-IR $(-1.3 \pm 0.1$ vs. $-0.8 \pm 0.2$ units; $p=0.02)$. After the second dietary intervention with a low-fat hypocaloric diet (Diet LF), only subjects with CC genotype showed a significant improvement in total cholesterol levels (CC vs. CG+GG) $(-15.3 \pm 1.4$ vs. $-6.1 \pm 1.3 \mathrm{mg} / \mathrm{dL} ; p=0.01)$, LDL cholesterol $(-14.6 \pm 1.8$ vs. $-6.4 \pm 1.3 \mathrm{mg} / \mathrm{dL} ; p=0.01)$, insulin levels $(-4.6 \pm 1.0$ vs. $-1.6 \pm 0.5 \mathrm{mU} / \mathrm{L} ; p=0.01)$, and HOMA-IR $(-1.6 \pm 0.1$ vs. $-1.0 \pm 0.2$ units; $p=0.02)$. Finally, in subjects with CC genotype, the improvement of insulin $(-3.3 \pm 0.6$ vs. -4.6 $\pm 1.0 \mathrm{mU} / \mathrm{L} ; p=0.01)$ and HOMA-IR $(-1.3 \pm 0.1$ vs. -1.6 \pm 0.1 units; $p=0.03)$ was lower with Diet HF than Diet LF.

Table 3 shows levels of adipokines. No differences were detected among baseline and posttreatment values of serum adipokine levels between both genotypes. Only subjects with CC genotype showed a significant increase of adiponectin levels after both diets (CC vs. CG+GG): Diet HF $(10.6 \pm 2.0$ vs. $1.8 \pm 1.0 \mathrm{ng} / \mathrm{dL} ; p=0.01)$ and Diet LF $(16.1 \pm 2.8$ vs. $1.3 \pm 1.0 \mathrm{ng} / \mathrm{dL} ; p=0.03)$. After both hypocaloric diets, leptin levels decreased in both genotypes in a similar degree.

\section{Discussion}

Our design has shown that the ADIPOQ variant rs266729 is significantly associated with the response of levels of insulin resistance, basal insulin, and adiponectin after weight loss secondary to two different moderate 
caloric restrictions with different amounts of dietary fat in obese subjects. Noncarriers of the G allele showed a better response of HOMA-IR, insulin, and adiponectin levels than $\mathrm{G}$ allele carriers after a high-fat hypocaloric diet. The same results were observed after a low-fat hypocaloric diet, but also with a significant improvement of LDL cholesterol and total cholesterol in noncarriers of allele G.

The relationship between this polymorphism (rs266729) and the presence of obesity and diabetes mellitus seems to be well established $[22,23]$. There are some interventional designs in the literature; some studies have been performed with a nonsurgical intervention [9-11] and others after a bariatric surgery $[12,13,24]$. One of the key aspects in studies with dietary intervention may be the distribution of macronutrients and especially the amounts of fat in the diet.

The design of some intervention studies has allowed evaluating the effect of weight loss without dietary modification when adding a drug to lose weight, for example sibutramine [11]. Hsiao et al. [11] showed a significantly greater weight loss for ADIPOQ rs266729 CC genotype compared to the placebo group during a 3-month period. This relationship of polymorphism with the amount of weight loss has not been found in our intervention study, perhaps because the populations were different. In our study of Caucasian subjects and in the mentioned Asian study, both populations had different basal genetic characteristics that can explain these findings. Another dietary study was an analysis of the Finnish Diabetes Prevention Program [9], a randomized, controlled multicenter study with a dietary intervention of reduction in the intake of total fat $<30 \%$ and saturated fat to $<10 \%$ of daily energy, and an increase of dietary fiber to at least $15 \mathrm{~g}$ per $1,000 \mathrm{kcal}$. The authors reported that $G$ allele carriers had higher weight after a 4-year follow-up and, surprisingly, $C$ allele carriers had an increased risk of developing diabetes mellitus type 2 . This unclear association, higher posttreatment body weight with lower diabetes mellitus, indicates therefore that the effect of this $A D I P O Q$ variant on glucose metabolism is independent of its effect on body weight. The diet of this intervention had a percentage of fat similar to our LF diet, but the distribution of unsaturated and polyunsaturated fats was not similar, and in addition, the intervention was 4 years, therefore the studies are not comparable either. Finally, in another intervention study [10] with a diet with a Mediterranean pattern and a macronutrient distribution very similar to the LF diet ( $25 \%$ lipids, $52 \%$ carbohydrates, and $23 \%$ proteins) a similar weight loss was detected in both genotypes, but obese patients with CC genotype had a greater increase in adiponectin levels and a greater decrease in LDL cholesterol, total cholesterol, insulin, and HOMA-IR levels than carriers of allele $\mathrm{G}$.

The results obtained in the studies with interventions of bariatric surgery are not comparable to the previous ones due to the great loss of weight obtained after the intervention. One study was carried out with a Roux-Y gastroenterostomy [12] in 60 morbid obese subjects over 32 months; subjects with $\mathrm{C}$ allele were more prone to show a reduction in LDL cholesterol levels $(-43 \%)$ than $\mathrm{G}$ allele carriers $(-18 \%)$. In this surgical intervention, weight loss was similar in both genotypes after bariatric surgery, as in our dietary study. Moreover, adiponectin levels were not determined. Another study with gastric banding surgery after 12 months [24] in 65 obese subjects did not show an effect of this genetic variant (rs266729) on circulating adiponectin concentrations. Finally, in the last interventional study over 3 years with biliopancreatic diversion [13], adiponectin concentrations increased after weight loss in CC subjects, which was not observed in carriers of the $G$ allele. Furthermore, CC genotype subjects showed a better improvement in lipid profile, insulin levels, and HOMA-IR than $G$ allele carriers.

The physiopathological mechanisms to explain the relationship of this genetic variant with modifications in levels of adiponectin and insulin metabolism after weight loss are poorly understood. Recent research results have indicated that the $\mathrm{G}$ allele alters the sequence for one transcriptional stimulatory protein binding site and secondarily reduces adiponectin promoter activity $[4,25]$ in both brown and white adipose tissues. In addition, the relationship between adiponectin levels and fat mass is well known [26]. In this context, a potential hypothesis is a gene-nutrient interaction. Ferguson et al. [27] have reported that the $\mathrm{G}$ allele for this genetic variant was identified as having degrees of insulin resistance and was highly responsive to differences in plasma saturated fatty acids. In another study [28], a gene-nutrient interaction was reported between the rs266729 variant of the ADIPOQ gene and the percentage of dietary calories derived from dietary fat. Perhaps dietary fatty acids could modulate the involvement of the adiponectin gene and its receptors in downstream pathways. In our study with two different amounts of dietary fatty but with the same profile of unsaturated and saturated dietary fats, we found a high improvement of insulin resistance after Diet LF than Diet HF. 
Limitations of our study included the recruitment of our obese subjects without diabetes mellitus and other cardiovascular risk factors or events. Second, we only analyzed one genetic variant of the ADIPOQ gene, so other ADIPOQ variants could be related with metabolic parameters. Third, other uncontrolled factors could be involved (e.g., epigenetic, hormonal status, and level of physical activity). Fourth, our findings were obtained in a small sample of Caucasian subjects, and ethnically matched studies should be performed to confirm our results. Finally, the self-reported dietary intake could be a potential bias of under- or over-reporting.

In conclusion, noncarriers of the $\mathrm{G}$ allele showed a better response of HOMA-IR, insulin, and adiponectin levels than $\mathrm{G}$ allele carriers after a high-fat hypocaloric diet. The same results were observed after a low-fat hypocaloric diet, but also with a significant improvement of LDL cholesterol and total cholesterol in noncarriers of allele G. Thus, a promising finding reported was that this $A D I P O Q$ gene variant might play an important role in modulating treatment outcomes with dietary interventions and an interaction with genetic variants in the development of obesity-related phenotypes. New dietary recommendations could be made based on the polymorphisms of the adiponectin gene, as has already been demonstrated in some studies [29].

\section{Statement of Ethics}

All procedures performed in studies involving human participants were in accordance with the ethical standards of the institutional and/or national research committee and with the $1964 \mathrm{Hel}-$ sinki Declaration and its later amendments or comparable ethical standards. Informed consent was obtained from all individual participants included in the study.

\section{Disclosure Statement}

The authors have no conflicts of interest to declare.

\section{Funding Sources}

No specific funding was received for this study.

\section{Author Contributions}

D.A. de Luis and R. Aller designed the study and performed the statistical analysis. O. Izaola carried out anthropometric evaluation and control of dietary intake. D. Primo carried out biochemical evaluation and genotyping.

\section{References}

1 Yang WS, Chuang LM. Human genetics of adiponectin in the metabolic syndrome. J Mol Med (Berl). 2006 Feb;84(2):112-21.

2 Cesari M, Narkiewicz K, De Toni R, Aldighieri E, Williams CJ, Rossi GP. Heritability of plasma adiponectin levels and body mass index in twins. J Clin Endocrinol Metab. 2007 Aug;92(8):3082-8.

3 Takahashi M, Arita Y, Yamagata K, Matsukawa Y, Okutomi K, Horie M, et al. Genomic structure and mutations in adipose-specific gene, adiponectin. Int $\mathrm{J}$ Obes Relat Metab Disord. 2000 Jul;24(7):861-8.

$4 \mathrm{Gu}$ HF. Biomarkers of adiponectin: plasma protein variation and genomic DNA polymorphisms. Biomark Insights. 2009 Oct;4: 123-33.

5 Bouatia-Naji N, Meyre D, Lobbens S, Séron K, Fumeron F, Balkau B, et al. ACDC/adiponectin polymorphisms are associated with severe childhood and adult obesity. Diabetes. 2006 Feb;55(2):545-50.

6 Yang M, Qiu CC, Chen W, Xu LL, Yu M, Xiang HD. Identification of a regulatory single nucleotide polymorphism in the adiponectin (APM1) gene associated with type 2 diabetes in Han nationality. Biomed Environ Sci. 2008 Dec;21(6):454-9.
7 Rasmussen-Torvik LJ, Pankow JS, Jacobs DR Jr, Steinberger J, Moran A, Sinaiko AR. The association of SNPs in ADIPOQ, ADIPOR1, and ADIPOR2 with insulin sensitivity in a cohort of adolescents and their parents. Hum Genet. 2009 Feb;125(1):21-8.

8 Wu LS, Hsieh CH, Pei D, Hung YJ, Kuo SW, Lin E. Association and interaction analyses of genetic variants in ADIPOQ, ENPP1, GHSR, PPARgamma and TCF7L2 genes for diabetic nephropathy in a Taiwanese population with type 2 diabetes. Nephrol Dial Transplant. 2009 Nov;24(11):3360-6.

9 Siitonen N, Pulkkinen L, Lindström J, Kolehmainen M, Eriksson JG, Venojärvi M, et al. Association of ADIPOQ gene variants with body weight, type 2 diabetes and serum adiponectin concentrations: the Finnish Diabetes Prevention Study. BMC Med Genet. 2011 Jan;12(1):5.

10 de Luis DA, Primo D, Izaola O, Gomez Hoyos E, Lopez Gomez JJ, Ortola A, et al. Role of the variant in adiponectin gene rs266729 on weight loss and cardiovascular risk factors after a hypocaloric diet with the Mediterranean pattern. Nutrition. 2019 Apr;60:1-5.

11 Hsiao TJ, Wu LS, Huang SY, Lin E. A common variant in the adiponectin gene on weight loss and body composition under sibutramine therapy in obesity. Clin Pharmacol. 2010;2:105-10.

12 Gasparotto AS, Borges DO, Zandoná MR, Ramos MJ, Meihnardt NG, Mattevi VS. Adiponectin promoter polymorphisms are predictors of lipid profile improvement after bariatric surgery. Genet Mol Biol. 2017 Oct-Dec; 40(4):736-42.

13 de Luis DA, Calvo SG, Pacheco D, Ovalle HF, Aller R. Adiponectin gene variant RS rs266729: relation to lipid profile changes and circulating adiponectin after bariatric surgery. Surg Obes Relat Dis. 2018 Sep;14(9): 1402-8.

14 Mataix J, Mañas M. Tablas de composición de alimentos españoles. Granada: University of Granada; 2003.

15 Duart Duart MJ, Arroyo CO, Moreno Frígols JL. Validation of a kinetic model for the reactions in RIA. Clin Chem Lab Med. 2002 Nov; 40(11):1161-7.

16 Matthews DR, Hosker JP, Rudenski AS, Naylor BA, Treacher DF, Turner RC. Homeostasis model assessment: insulin resistance and beta-cell function from fasting plasma glucose and insulin concentrations in man. Diabetologia. 1985 Jul;28(7): 412-9. 
17 Friedewald WT, Levy RI, Fredrickson DS. Estimation of the concentration of low-density lipoprotein cholesterol in plasma, without use of the preparative ultracentrifuge. Clin Chem. 1972 Jun;18(6):499-502.

18 Pfützner A, Langenfeld M, Kunt T, Löbig M, Forst T. Evaluation of human resistin assays with serum from patients with type 2 diabetes and different degrees of insulin resistance. Clin Lab. 2003;49(11-12):571-6.

19 Suominen P. Evaluation of an enzyme immunometric assay to measure serum adiponectin concentrations. Clin Chem. 2004 Jan;50(1): 219-21.

20 Lukaski HC, Johnson PE, Bolonchuk WW, Lykken GI. Assessment of fat-free mass using bioelectrical impedance measurements of the human body. Am J Clin Nutr. 1985 Apr;41(4): 810-7.

21 Khan SS, Smith MS. reda D, Suffredini AF, Mc Coy JP. Multiplex bead array assays for detection of soluble cytokines: comparisons of sensitivity and quantitative values among kits from multiple manufacturers. Cytometry B Clin Cytom. 2004 Sep;61(1):35-9.
22 Sun P, Liu L, Chen J, Chen Y, Shi L, Imam MU, et al. The polymorphism of rs266729 in adiponectin gene and type 2 diabetes mellitus: A Meta-Analysis. Medicine (Baltimore). 2017 Nov;96(47):e8745.

23 Zhou JM, Zhang M, Wang S, Wang BY, Han CY, Ren YC, et al. Association of the ADIPOQ Rs2241766 and Rs266729 Polymorphisms with Metabolic Syndrome in the Chinese Population: A Meta-analysis. Biomed Environ Sci. 2016 Jul;29(7):505-15.

24 Poitou C, Lacorte JM, Coupaye M, Bertrais S, Bedel JF, Lafon N, et al. Relationship between single nucleotide polymorphisms in leptin, IL6 and adiponectin genes and their circulating product in morbidly obese subjects before and after gastric banding surgery. Obes Surg. 2005 Jan;15(1):11-23.

25 Kadowaki T, Yamauchi T, Kubota N, Hara K, Ueki K, Tobe K. Adiponectin and adiponectin receptors in insulin resistance, diabetes, and the metabolic syndrome. J Clin Invest. 2006 Jul;116(7):1784-92.
26 Whitehead JP, Richards AA, Hickman IJ, Macdonald GA, Prins JB. Adiponectin - a key adipokine in the metabolic syndrome. Diabetes Obes Metab. 2006 May;8(3):264-80.

27 Ferguson JF, Phillips CM, Tierney AC, PérezMartínez P, Defoort C, Helal O, et al. Genenutrient interactions in the metabolic syndrome: single nucleotide polymorphisms in ADIPOQ and ADIPOR1 interact with plasma saturated fatty acids to modulate insulin resistance. Am J Clin Nutr. 2010 Mar;91(3):794801.

28 Santos JL, Boutin P, Verdich C, Holst C, Larsen LH, Toubro $\mathrm{S}$, et al.; NUGENOB* consortium. Genotype-by-nutrient interactions assessed in European obese women. A case-only study. Eur J Nutr. 2006 Dec;45(8):454-62.

29 Alsaleh A, Crepostnaia D, Maniou Z, Lewis FJ, Hall WL, Sanders TA, et al. MARINA study team. Adiponectin gene variant interacts with fish oil supplementation to influence serum adiponectin in older individuals. J Nutr. 2013 Jul;143:1021-7. 